\title{
CYP2D6 ALLELE DISTRIBUTION IN MACEDONIANS, ALBANIANS AND ROMANIES IN THE REPUBLIC OF MACEDONIA
}

Kuzmanovska M, Dimishkovska M, Maleva Kostovska I, Noveski P, Sukarova Stefanovska E, Plaseska-Karanfilska D*

*Corresponding Author: Dijana Plaseska-Karanfilska, M.D., Ph.D., Research Centre for Genetic Engineering and Biotechnology "Georgi D. Efremov," Macedonian Academy of Sciences and Arts, Krste Misirkov 2, 1000 Skopje, Republic of Macedonia. Tel: +389-2-3235-410. Fax: +389-2-3115-434. E-mail: dijana@manu.edu.mk

\begin{abstract}
Cytochrome P450 2D6 (CYP2D6) is an enzyme of great importance for the metabolism of clinically used drugs. More than 100 variants of the CYP2D6 gene have been identified so far. The aim of this study was to investigate the allele distribution of CYP2D6 gene variants in 100 individuals of each of the Macedonian, Albanian and Romany population, by genotyping using long range polymerase chain reaction (PCR) and a multiplex single base extension method. The most frequent variants and almost equally distributed in the three groups were the fully functional alleles $* 1$ and $* 2$. The most common non functional allele in all groups was *4 that was found in $22.5 \%$ of the Albanians. The most common allele with decreased activity was $* 41$ which was found in $23.0 \%$ of the Romany ethnic group, in $11.0 \%$ of the Macedonians and in $10.5 \%$ of the Albanians. Seven percent of the Albanians, $6.0 \%$ of the Romani and $4.0 \%$ of the Macedonians were poor metabolizers, while $5.0 \%$ of the Macedonians, $1.0 \%$ of Albanians and $1.0 \%$ of the Romanies were ultrarapid metabolizers. We concluded that the CYP2D6 gene locus is highly heterogeneous in these groups and that the prevalence of the CYP2D6 allele variants and genotypes in the Republic of Macedonia is in accordance with that of other European populations.
\end{abstract}

\footnotetext{
* Research Centre for Genetic Engineering and Biotechnology "Georgi D. Efremov," Macedonian Academy of Sciences and Arts, Skopje, Republic of Macedonia
}

Keywords: Allele; $C Y P 2 D 6$ gene; $C Y P 450$; Ethnic groups; Extensive metabolizers (EMs); Intermediate metabolizers (IMs); Poor metabolizers (PMs); Ultrarapid metabolizers (UMs).

\section{INTRODUCTION}

Physiological responses to the same drug are known to vary substantially between different individuals. Although this may result from environmental and physiological factors or drug-drug interactions, in many cases the response is inherited and arises from a polymorphism in genes that encode drug transporters, drug receptors, and especially, drugmetabolizing enzymes [1]. Of the genes that encode drug-metabolizing enzymes, CYP2D6, a member of the cytochrome $P 450$ superfamily (CYP450), is well characterized.

Approximately 57 CYP genes that encode cytochrome $\mathrm{P} 450$ proteins and 58 pseudogenes are present in the human genome and are classified into distinct families and subfamilies according to their sequence similarity [2]. The CYP2D subfamily comprises the CYP2D6 gene and two pseudogenes (CYP2D7 and CYP2D8), located in tandem on chromosome 22q13.1, at the 3' end of the CYP2D cluster. The CYP2D6 gene contains nine exons comprised of 1461 codons. The evolution of this locus has involved elimination of three genes and inactivation of two neighboring genes (CYP2D7 and CYP2D8), all of which display $92.0-97.0 \%$ nucleotide similarity across their sequences [3]. The CYP2D6 gene medi- 
ates the metabolism of almost a quarter of drugs in common clinical use, including opiate analgesics, antiarrhythmics, antipsychotics, antidepressants, tamoxifen and $\beta$ blockers [1].

The CYP2D6 gene is highly polymorphic, with more than 100 variations and numerous subvariants having been identified [4]. These variations include: single-base changes, short insertions and deletions, major deletions [5] and whole gene duplications [6].

There are four major phenotype classes: ultrarapid metabolizers (UMs), extensive metabolizers (EMs), poor metabolizers (PMs) and intermediate metabolizers (IMs) and two subclasses: IMS to EMs and PMs to IMs. The sub-classification of the intermediate metabolizers is ascribed to the wide spectrum of metabolic activity that can range from marginally better than the PM phenotype to activity that is close to that of the EM phenotype (Table 1) $[4,7]$.

The EM phenotype is expressed by the majority of the population and is therefore considered "the norm" [8]. Poor metabolizers inherit two null $C Y$ $P 2 D 6$ alleles that include at least 22 different alleles which do not encode a functional protein and show no detectable residual enzymatic activity. This leads to accumulation of high levels of unmetabolized drugs that are CYP2D6 substrates, greater potential for adverse effects and drug-drug interactions, and lower efficacy of drugs that require CYP2D6 activation [9]. The UM phenotype is caused by amplification of active $C Y P 2 D 6$ genes, primarily the $C Y P 2 D 6^{*} 1$ and $C Y P 2 D 6 * 2$ alleles. Individuals with this phenotype metabolize drugs at an ultrarapid rate, which may lead to loss of therapeutic efficacy at standard doses [10]. Individuals who are heterozygous for a defective and a fully active CYP2D6 allele or are homozygous for an allele with decreased activity, for example alleles $* 10, * 17, * 36$ and $* 41$, often demonstrate an IM phenotype [11]. Previous genetic studies showed high levels of CYP2D6 polymorphism, both within and between populations [12], and a surprisingly high frequency of null and reduced function variants.

Poor metabolizers account for 5.0 to $10.0 \%$ of the Caucasian population and less than $1.0 \%$ of the Asian population [13]. In Caucasians, common deficient alleles include CYP $2 D 6 * 3, * 4, * 5$ and $* 6$, accounting for about $98.0 \%$ of PMs [14]. On the other hand, the decreased activity allele $* 41$ is predominantly present in the Middle East, with frequencies reaching up to $22.5 \%$ [15].

In contrast to PMs, UMs usually carry a duplicated, or even multiduplicated (up to 13 copies of $C Y P 2 D 6)$ active $C Y P 2 D 6$ allele $(C Y P 2 D 6 * x N)$. The frequencies of $C Y P 2 D 6^{*} x N$ vary greatly between races [16]. Both $C Y P 2 D 6^{*} 5$ and $C Y P 2 D 6^{*} x N$ result from CYP2D6 gene rearrangement [17] and comprise CYP2D6 gene copy number variations.

The CYP2D6 genotyping to predict metabolic status is considered a valid alternative to traditional phenotyping methods [18]. Assessing the CYP2D6 genotype also offers several distinct advantages over the experimental determination of a CYP2D6 phenotype [19]. Genotyping usually requires only a blood sample and can be done before a drug is given to a patient. It therefore may facilitate improved drug efficiency and diminished risk for adverse drug reactions [20]. The aim of this study was to investigate the allele distribution of CYP2D6 variants in Macedonian, Albanian and Romany populations as well

Table 1. CYP2D64 major phenotype classes and two subclasses $[4,7]^{\mathrm{a}}$.

\begin{tabular}{|c|c|}
\hline $\begin{array}{l}\text { Predicted Drug } \\
\text { Metabolizing Phenotype }^{\text {b }}\end{array}$ & Combination of Alleles \\
\hline UM & A combination of one normal activity allele with one increased activity allele \\
\hline EM & $\begin{array}{l}\text { Two normal activity alleles; a combination of one increased activity allele with one decreased } \\
\text { activity allele }\end{array}$ \\
\hline IM to EM & $\begin{array}{l}\text { A combination of one normal activity allele with one decreased activity allele; a combination of one } \\
\text { increased activity allele with one null activity allele }\end{array}$ \\
\hline IM & One normal activity allele with one null activity allele; two decreased activity alleles \\
\hline PM to IM & A combination of one decreased activity allele with one null activity allele \\
\hline PM & Only null activity alleles detected \\
\hline
\end{tabular}

a The phenotypes were derived from the Human Cytochrome P450 (CYP) Allele Nomenclature Committee website [4] and the PharmGKB website for the related Clinical Pharmacogenetics Implementation Consortium guidelines for CYP2D6 [7].

${ }^{\mathrm{b}}$ UM: ultrarapid metabolizer; EM: extensive metabolizer; IM: intermediate metabolizer; PM: poor metabolizer. 
as to implement our findings in the clinical practice in the Republic of Macedonia.

\section{MATERIALS AND METHODS}

DNA Samples. DNA material for genotyping from Macedonians $(n=100)$, Albanians $(n=100)$ and Romanies $(n=100)$, was obtained from the DNA bank of the Research Centre for Genetic Engineering and Biotechnology "Georgi D. Efremov" at the Macedonian Academy of Science and Arts, Skopje, Republic of Macedonia. We decided to analyze 100 samples from each ethnicity, in order to be able to compare and statistically process the obtained results. The number of samples from each ethnic group does not reflect the actual representation of ethnicities in the Republic of Macedonia. The Ethics Committee of the Macedonian Academy of Science and Arts approved this study. The samples were anonymized after collection.

CYP2D6 Genotyping. The genotyping was performed following a recently described protocol by Sistonen et al. [21], based on a combination of long range polymerase chain reaction (PCR), to detect whole-gene deletion/ duplication and multiplex extension of unlabeled oligo-nucleotide primers with fluorescently labeled dideoxynucleotide triphosphates (ABI PRISM ${ }^{\circledR}$ SNaPshot Multiplex Kit; Life Technologies, Carlsbad, CA, USA) to characterize 11 relevant polymorphic positions in the coding region of $C Y P 2 D 6$. This made it possible to identify $C Y P$ $2 D 6$ variants which are highly represented in different human populations (i.e., $* 2, * 4, * 10, * 17, * 29, * 39$, $* 41$ ), rare variants known to be responsible for low or null metabolic activity (i.e., *3,*6 and *9), and whole gene deletion $(* 5)$ and duplications $(* 1 x N$, $* 2 x N)$. This permitted us to identify the mutations that are generally thought to comprise more than $90.0 \%$ of known variants in Europeans [22], and mutation $1023(\mathrm{C}>\mathrm{T})$ which is rare in Europe, but is common in African populations. The haplotypes which did not show any of these mutations were classified as $* 1$.

Three parallel long range-PCRs were run for each sample using Expand Long Template PCR System (Roche Diagnostics, Basel, Switzerland). We obtained a $5.1 \mathrm{~kb}$ fragment containing all nine $C Y P 2 D 6$ exons using $C Y P 2 D 6-F[21]$ and $C Y P 2 D 6-R$ primers [21]. This product was used as a template in order to be able to type 11 positions in one reaction, based on single-base primer extension with fluorescentlylabelled ddNTPs (ABI PRISM ${ }^{\circledR}$ SNaPshot Multiplex Kit; Life Technologies).

The $25 \mu \mathrm{L}$ reaction mixture contained $2 \mathrm{U}$ enzyme mix, Expand Long Template Buffer 1, $2 \times$ concentrated, with $17.5 \mathrm{mM} \mathrm{MgCl}_{2}, 0.2 \mathrm{mM}$ each dideoxynucleotide triphosphate, $0.4 \mu \mathrm{M}$ of each primer, and $50 \mathrm{ng}$ of genomic DNA. The PCR reaction was conducted as follows: denaturation at $94^{\circ} \mathrm{C}$ for 10 min., 10 cycles at $94^{\circ} \mathrm{C}$ for 30 seconds and $68^{\circ} \mathrm{C}$ for 30 seconds, 25 cycles at $94^{\circ} \mathrm{C}$ for 30 seconds and $68^{\circ} \mathrm{C}$ for $10 \mathrm{~min}$. and 15 seconds, plus 15 seconds per cycle, and a final extension at $68^{\circ} \mathrm{C}$ for $30 \mathrm{~min}$.

The long range-PCR products were analyzed on $0.8 \%$ agarose gels, and the $5.1 \mathrm{~kb}$ fragments were purified by use of $1 \mu \mathrm{L}$ of ExoSAP-IT (USB, Affymetrix Inc., San Diego, CA, USA) overnight at $37^{\circ} \mathrm{C}(2 \mu \mathrm{L}$ PCR product $+1 \mu \mathrm{L}$ Exo SAP IT $)$. The reaction ended with inactivation of the enzyme at $86^{\circ} \mathrm{C}$ for $20 \mathrm{~min}$.

The purified $5.1 \mathrm{~kb}$ product was used as template in the SNaPshot (Life Technologies) reaction. In the following single-base extension reaction, the detection primers annealed adjacent to the single nucleotide polymorphism (SNP) position and was extended with fluorescently- labeled dideoxynucleotide triphosphates. The SNaPshot (Life Technologies) reaction contained $3.0 \mu \mathrm{L}$ of purified PCR product, $1 \mu \mathrm{L}$ of pooled detection primers [21], $1 \mu \mathrm{L}$ water and $1 \mu \mathrm{L}$ of SNaPshot (Life Technologies) ready reaction mixture in a final volume of $7 \mu \mathrm{L}$. The cycling profile was 25 cycles at $96^{\circ} \mathrm{C}$ for 10 seconds, $55^{\circ} \mathrm{C}$ for 10 seconds and $60^{\circ} \mathrm{C}$ for 30 seconds. After the reaction, 5-phosphoryl groups of unincorporated dideoxynucleotide triphosphates were removed by addition of SAP (shrimp alkaline phosphatase) (USB, Affymetrix Inc.) for 1 hour at $37^{\circ} \mathrm{C}$, followed by enzyme inactivation at $86^{\circ} \mathrm{C}$ for $20 \mathrm{~min}$. Capillary electrophoresis of samples was performed on the ABI PRISM ${ }^{\circledR} 3130$ genetic analyzer with LIZ120 (Life Technologies) as a size standard. The obtained results were analyzed with GeneScan 4.0 software (Life Technologies).

Two additional long range-PCR reactions were used to analyze the major rearrangements, i.e., duplication or deletion of the entire CYP2D6 gene [21]. Both deletion and duplication PCR reactions were performed in a reaction volume of $12 \mu \mathrm{L}$ containing $1 \mathrm{U}$ enzyme mix from the Expand Long Template 
PCR System (Roche Diagnostics), Long Template Buffer $1,1 \times$ concentrated, with $17.5 \mathrm{mM} \mathrm{MgCl}$, and $0.2 \mathrm{mM}$ each dideoxynucleotide triphosphate. The primer concentrations were as follows: for the duplication-specific reaction, $0.3 \mu \mathrm{M} C Y P-207-F$,

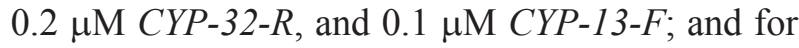
the deletion-specific reaction, $0.3 \mu \mathrm{M} \mathrm{CYP-13-F,0.2}$ $\mu \mathrm{M} C Y P-24-R$, and $0.1 \mu \mathrm{M} C Y P-207-F$. The cycling profile was as described above.

The primers $C Y P-13-F$ and $C Y P-24-R$ generated a deletion-specific fragment of $3.5 \mathrm{~kb}$, while primers $C Y P-24-R$ and $C Y P-207-F$ yielded a control fragment of $3.0 \mathrm{~kb}$. With the deletion-specific PCR we analyzed 94 homozygous samples. We analyzed only these samples because they had only one peak for each of the 11 analyzed polymorphic sites and we could not determine the difference between a homozygous set of polymorphic sites or a deleted allele (Figure 1). In comparison, the heterozygous patients had two peaks on at least one polymorphic site, indicating the presence of two alleles. We also analyzed 60 heterozygous samples in order to confirm our hypothesis.

We looked for CYP2D6 gene duplications using the $C Y P-207-F$ and $C Y P-32-R$ primer pair. With these primers, we amplified a duplication-specific fragment of $3.2 \mathrm{~kb}$. Simultaneously, a control fragment of 3.8 $\mathrm{kb}$ was amplified with the $C Y P-13-F$ forward primer. Apart from the duplication-specific PCR, we also confirmed the detected duplications with a comparison of the ratios of the two peaks that appeared at the same position for each separate polymorphic site. By comparing two electropherograms obtained from the $\mathrm{SNaP}$ shot (Life Technologies) analysis, we noticed that the duplicated allele could readily be identified as the one of interest, as it displayed higher signals in the polymorphic heterozygous sites (Figure 2A and 2B) [21].

The $\chi^{2}$ test and Fisher's exact test were used to compare frequencies between populations. GraphPad InStat software (version 3.1; http://www.graphpad. com) was used for statistical analysis. A $p$ value of 0.05 was considered significant.

\section{RESULTS}

Table 2 summarizes the allele frequencies of the three groups. Of the fully functional alleles, the most frequent variant was the wild type allele * 1 (in $36.5 \%$ of Macedonians, $33.0 \%$ of Romanies and $37.0 \%$ of Albanians), followed by allele $* 2$ (in $25.5 \%$ of Macedonians, $21.5 \%$ of Romanies and $25.5 \%$ of Albanians).

The decreased activity alleles were observed in $23.5 \%$ of the Romany population, in $14.0 \%$ of the Macedonian and in $11.5 \%$ of the Albanian. Four decreased activity alleles were detected, i.e., $* 9, * 10$, $* 29$ and $* 41$, from which allele $* 41$ stood out as the most frequent variant. The frequency of the allele $* 41$ in the Romanies $(23.0 \%)$ is higher in comparison with the Macedonians (11.0\%) and Albanians (10.5\%), and this difference is statistically significant $(p=$

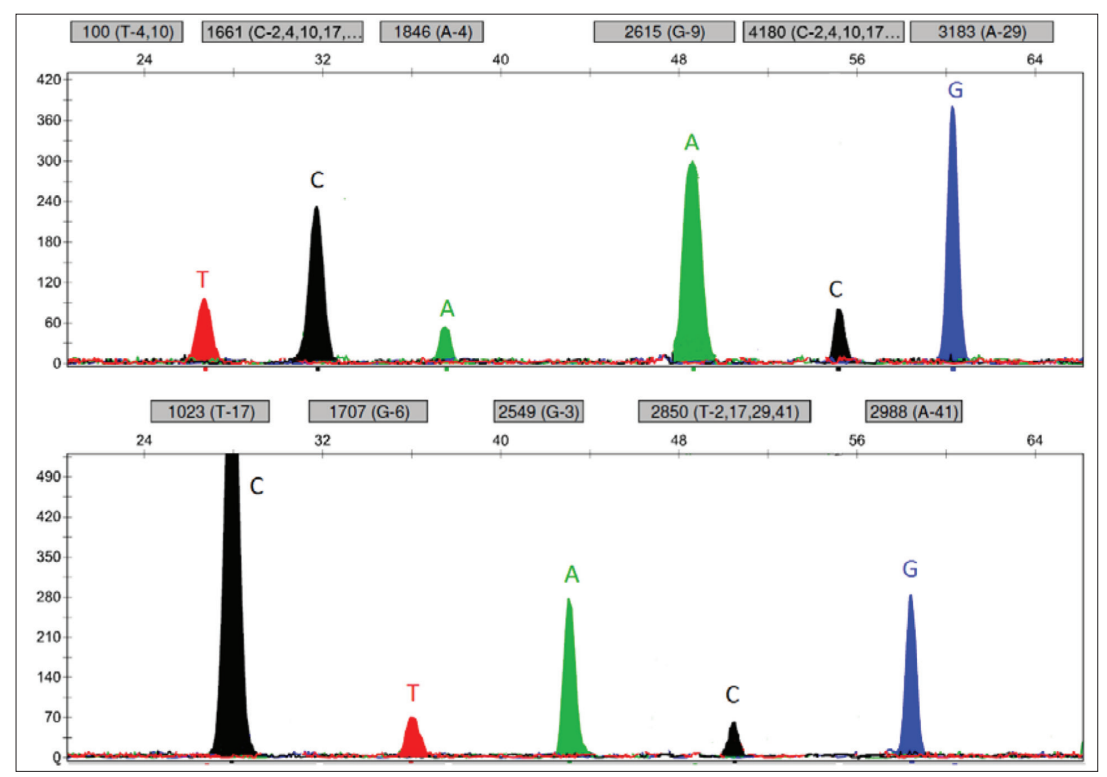

Figure 1. Representative electropherogram of homozygous patient with genotype $* 4 / 4$. 
0.002 and $p=0.0012$, respectively). The $* 9$ allele was detected only in the Romany $(0.5 \%)$ and the Albanian population $(0.5 \%)$, whereas the $* 10$ allele was present exclusively in the Macedonian and Albanian population with frequencies of 1.5 and $0.5 \%$, respectively. The $* 29$ allele was observed solely in the Macedonian ethnic group (1.5\%).

Non functional alleles were found in $30.0 \%$ of the Albanians, $21.5 \%$ of the Macedonians and $17.5 \%$ of the Romanies. The non functional $* 4$ allele was found in $22.5 \%$ of the Albanians, $17.0 \%$ of the Macedonians and $15.0 \%$ of the Romanies. Alleles $* 3, * 5$ and $* 6$ were present in $3.5,2.5$ and $1.5 \%$, respectively, of the Albanians, in 2.0, 1.5 and 1.0\%, respectively, of the Macedonians, and in 1.5, 0.5 and $0.5 \%$, respectively, of the Romanies.

Five duplications (four $* 1 x N$ alleles and one $* 2 x N$ allele) were identified in the Macedonian group. Only one duplication was found in each of the Albanian $(* 2 x N)$ and Romany $(* 1 x N)$ groups.

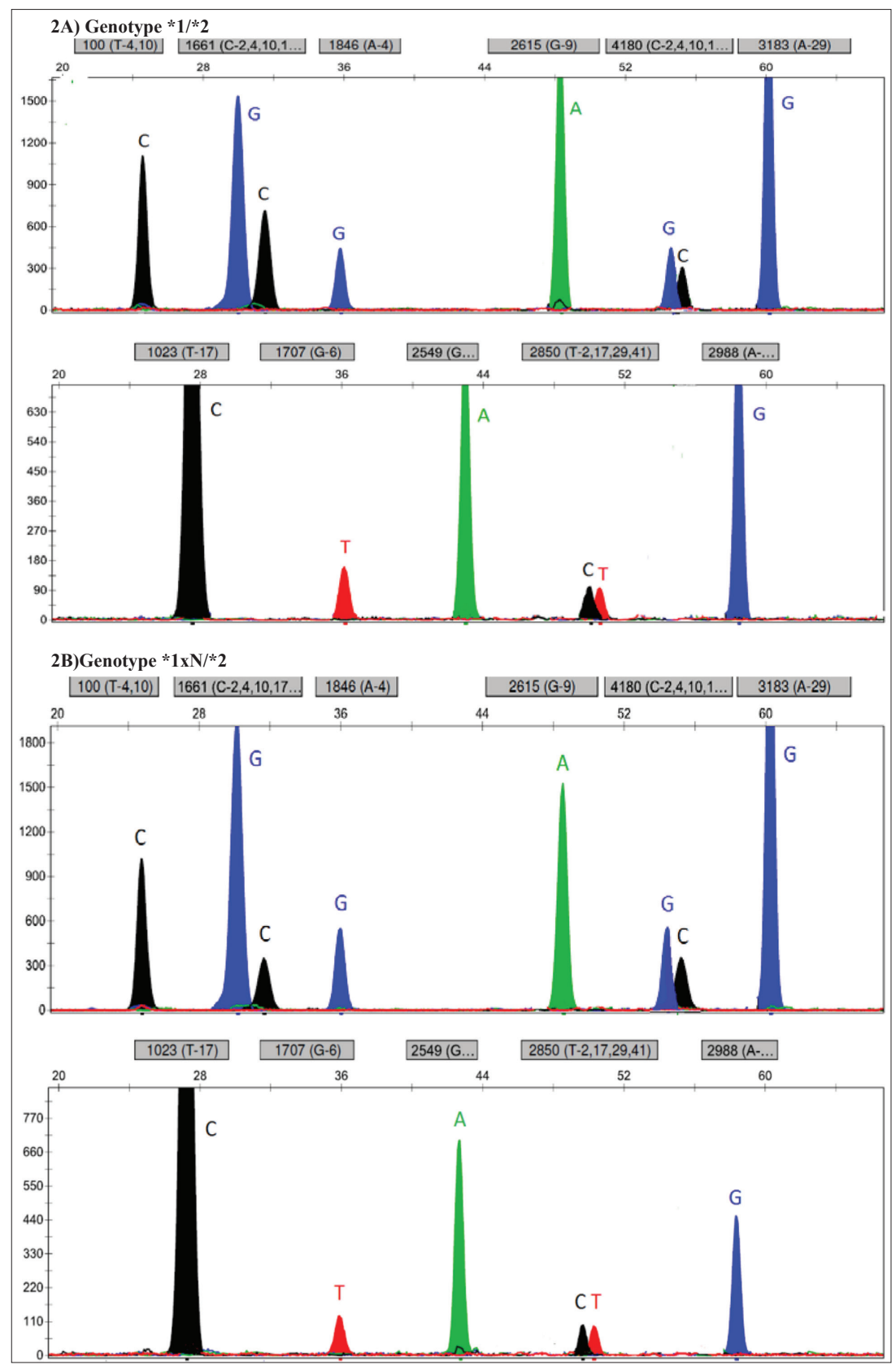

Figure 2. A) Representative electropherogram of a heterozygous patient without a duplication. B) Representative electropherogram of a heterozygous patient with a duplication. 
Table 3 summarizes the CYP2D6 genotypes and corresponding phenotypes found in the three groups. The $* 1 / * 2$ genotype was present in $20.0 \%$ of the Macedonian and in $17.0 \%$ of the Romany group. The $1 / * 4$ genotype was present in $17.0 \%$ of the Albanian group. We yielded statistically significant results for the frequency of the genotypes $* 1 / * 41$ and $* 2 / * 41$, which were found in 12.0 and $17.0 \%$, respectively, of the Romany and in $5.0 \%$ for each genotype in the Macedonians ( $p=0.013$ and $p=0.0357$, respectively) (Table 3 ).

\section{DISCUSSION}

The $C Y P 2 D 6$ gene is of great interest for clinical practice because it is responsible for the metabolism of many commonly used drugs and its genetic polymorphism can have a strong effect on the substrate and lead to wide inter-individual variation. Variation in CYP2D6 activity has important therapeutic consequences and can play a significant role in the development of adverse events or therapeutic failure in susceptible individuals.

The knowledge of how a drug is metabolized and which enzymes are involved helps to predict drugdrug interactions and how fast an individual patient may metabolize a specific drug. Because CYP2D6 metabolizes at least $25.0 \%$ of the marketed drugs, including selective serotonin reuptake inhibitors
(SSRI), tricylic antidepressants (TCA), $\beta$ blockers, opiates, neuroleptics, tamoxifen and antiar-rhythmics, there are possible issues of drug interaction in vivo which are of clinical significance.

The $C Y P 2 D 6^{*} 3, C Y P 2 D 6^{*} 4$ and $C Y P 2 D 6^{*} 6$ are the most important non functional alleles that are predominantly responsible for the poor metabolizing capacity. These alleles are found in $90.0-95.0 \%$ of the PMs in Europe [23]. The results obtained in our study showed that the prevalence of the CYP $2 D 6^{*} 4$ allele frequency is in accordance with that of other European populations, which vary between 12.0 and $21.0 \%$. The frequency values for the allele $* 4$ range between $15.0 \%$ in Romanies, $17.0 \%$ in Macedonians and $22.5 \%$ in Albanians (Table 4).

From the alleles with severely reduced activity, the results we acquired show an increased frequency of allele $* 41(23.0 \%)$ in Romanies. These frequencies are in correlation with the values obtained from several studies conducted in the Middle East [2426]. These results are not surprising given the Indian origin of the Romany population and their migration through the Middle East, before they reached the Balkans.

Our results showed similar percentages of deletions and duplications in comparison with the other European populations. In the Albanian ethnic group we noticed the highest number of deletions, reaching

Table 2. CYP2D6 allele frequency in Macedonians, Albanians and Romanies.

\begin{tabular}{|c|c|c|c|c|c|c|c|}
\hline \multirow{2}{*}{ Allele and SNP } & \multirow{2}{*}{ Location } & \multirow{2}{*}{$\begin{array}{l}\text { Amino Acid } \\
\text { Change }\end{array}$} & \multirow{2}{*}{ dbSNP ID } & \multirow{2}{*}{$\begin{array}{c}\text { Functional } \\
\text { Effect }\end{array}$} & \multicolumn{3}{|c|}{ Allele Frequency } \\
\hline & & & & & Macedonians & Albanians & Romanies \\
\hline *1: wild type & - & - & - & normal & 0.365 & 0.370 & 0.330 \\
\hline $\begin{array}{c}* 2: 2850(\mathrm{C}>\mathrm{T}) \\
4180(\mathrm{G}>\mathrm{C})\end{array}$ & $\begin{array}{l}\text { exon } 2 \\
\text { exon } 6\end{array}$ & $\begin{array}{l}\text { Arg296Cys } \\
\text { Ser486Thr }\end{array}$ & $\begin{array}{c}\text { rs } 16947 \\
\text { rs } 1135840\end{array}$ & normal & 0.255 & 0.215 & 0.255 \\
\hline *3: 2549delA & exon 5 & frameshift & rs35742686 & none & 0.020 & 0.035 & 0.015 \\
\hline$* 4: 1846(\mathrm{G}>\mathrm{A})$ & $\begin{array}{c}\text { intron } 3 \text { - exon } 4 \\
\text { junction }\end{array}$ & splicing defect & rs3892097 & none & 0.170 & 0.225 & 0.150 \\
\hline$* 5$ & - & gene deletion & - & none & 0.015 & 0.025 & 0.005 \\
\hline$* 6: 1707 \mathrm{delT}$ & - & frameshift & rs5030655 & none & 0.010 & 0.015 & 0.005 \\
\hline *9: 2615-2617delAAG & - & Lys281del & rs5030656 & decreased & 0.000 & 0.005 & 0.005 \\
\hline$* 10: 100(C>T)$ & exon 1 & Pro34Ser & rs1065852 & decreased & 0.015 & 0.005 & 0.000 \\
\hline$* 17: 1023(C>T)$ & exon 2 & Thr107Ile & rs28371706 & decreased & 0.000 & 0.000 & 0.000 \\
\hline *29: $1661(\mathrm{G}>\mathrm{C})$ & - & Arg36His & rs61736512 & decreased & 0.015 & 0.000 & 0.000 \\
\hline$* 41: 2988(\mathrm{G}>\mathrm{A})$ & - & Glu242Lys & rs28371725 & decreased & 0.110 & 0.105 & 0.230 \\
\hline$* 1 x N$ & - & gene duplication & - & increased & 0.020 & 0.000 & 0.005 \\
\hline$* 2 x N$ & - & gene duplication & - & increased & 0.005 & 0.005 & 0.000 \\
\hline
\end{tabular}

SNP: single nucleotide polymorphism; dbSNP: database SNP. 
Table 3. Genotype frequency of determined CYP2D6 genotypes and corresponding phenotypes.

\begin{tabular}{|c|c|c|c|c|}
\hline Predicted & Genotype & $\begin{array}{c}\text { Frequency in } \\
\text { Macedonians (\%) }\end{array}$ & $\begin{array}{c}\text { Frequency in } \\
\text { Albanians (\%) }\end{array}$ & $\begin{array}{r}\text { Frequency in } \\
\text { Romanies (\%) }\end{array}$ \\
\hline \multirow{3}{*}{ Ultrarapid metabolizer } & $* 1 x N^{\prime} * 1$ & 0.01 & 0.00 & 0.00 \\
\hline & $* 1 x N / * 2$ & 0.03 & 0.00 & 0.01 \\
\hline & $* 2 x N / * 2$ & 0.01 & 0.01 & 0.00 \\
\hline \multirow{10}{*}{ Extensive metabolizer } & $* 1 / * 1$ & 0.14 & 0.15 & 0.13 \\
\hline & $* 1 / * 2$ & 0.20 & 0.13 & 0.17 \\
\hline & $* 1 / * 9$ & 0.00 & 0.00 & 0.01 \\
\hline & $* 1 / * 10$ & 0.02 & 0.00 & 0.00 \\
\hline & $* 1 / 29$ & 0.01 & 0.00 & 0.00 \\
\hline & $* 2 / * 29$ & 0.01 & 0.00 & 0.00 \\
\hline & $* 1 / * 41$ & 0.05 & 0.08 & 0.12 \\
\hline & $* 2 / * 2$ & 0.06 & 0.05 & 0.07 \\
\hline & $* 2 / * 3$ & 0.01 & 0.02 & 0.00 \\
\hline & $* 2 / * 41$ & 0.05 & 0.03 & 0.17 \\
\hline \multirow{15}{*}{ Intermediate metabolizer } & $* 1 / * 3$ & 0.01 & 0.03 & 0.01 \\
\hline & $* 1 / * 4$ & 0.13 & 0.17 & 0.07 \\
\hline & $* 1 / * 5$ & 0.02 & 0.02 & 0.01 \\
\hline & $* 1 / * 6$ & 0.00 & 0.02 & 0.01 \\
\hline & $* 2 / * 4$ & 0.09 & 0.12 & 0.02 \\
\hline & $* 2 / * 5$ & 0.01 & 0.00 & 0.00 \\
\hline & $* 2 / * 6$ & 0.00 & 0.01 & 0.00 \\
\hline & $* 41 / * 41$ & 0.03 & 0.02 & 0.03 \\
\hline & $* 9 / * 41$ & 0.00 & 0.01 & 0.00 \\
\hline & $* 4 / * 41$ & 0.04 & 0.04 & 0.09 \\
\hline & $* 4 / 29$ & 0.01 & 0.00 & 0.00 \\
\hline & $* 6 / * 10$ & 0.01 & 0.00 & 0.00 \\
\hline & $* 6 / * 41$ & 0.01 & 0.00 & 0.00 \\
\hline & $* 3 / * 41$ & 0.00 & 0.01 & 0.02 \\
\hline & $* 4 / * 10$ & 0.00 & 0.01 & 0.00 \\
\hline \multirow{4}{*}{ Poor metabolizer } & $* 3 / * 3$ & 0.01 & 0.00 & 0.00 \\
\hline & $* 3 / * 4$ & 0.00 & 0.01 & 0.00 \\
\hline & $* 4 / * 5$ & 0.00 & 0.03 & 0.00 \\
\hline & $* 4 / * 4$ & 0.03 & 0.03 & 0.06 \\
\hline
\end{tabular}

frequency of $2.5 \%$ and in the Macedonian ethnic group the highest number of duplication (2.5\%) (Table 4).

Our study is not the first one that has reviewed the frequency distribution of the CYP2D6 alleles in the Republic of Macedonia, still it is the first one that was conducted for each ethnicity separately. The prevalence values for the polymorphic alleles CYP 2D6*3, *4, *6, *9 and *10 (0.008, 0.187, 0.0, 0.016 and 0.027 , respectively) reported by Kapedanovska Nestorovska et al. [27] are in agreement with our results. However, the results for deletions and duplications in the two studies were not in concordance.
Kapedanovska Nestorovska et al. [27] reported high frequencies of deletions and duplications $(0.091$ and 0.059 , respectively) which are not in concordance with our study (Table 4). The method that Kapedanovska Nestorovska et al. [27] used for detection of the duplications and deletions was the quantitative real-time PCR method, using TaqMan Copy Number Assay (Thermo Fisher Scientific, Waltham, MA, USA). One of the main limitations of real-time PCR is the increased risk of false positive results, so this discordance is probably due to the lack of specificity and sensitivity of the method used. 


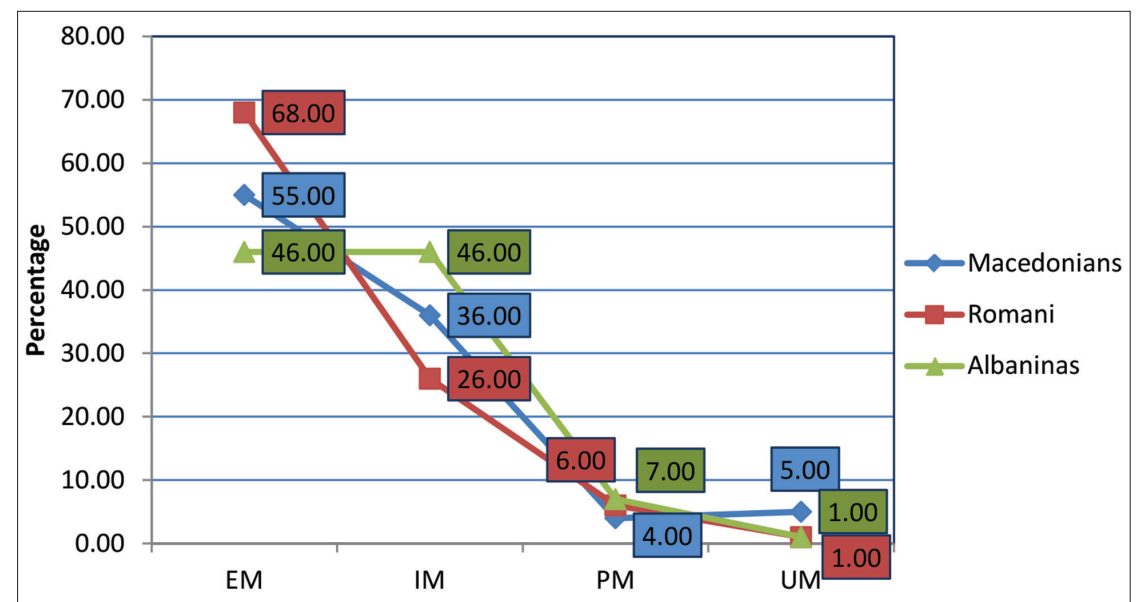

Figure 3. The calculated percentage of metabolizing classes within the Macedonian, Albanian and Romany population (EM: extensive metabolizers; IM: intermediate metabolizers; PM: poor metabolizers; UM: ultrarapid metabolizers).

The metabolizing classes that are of pharmacological interest include the group of PMs and UMs. It is important to point out that the Albanians topped the list as the group with the highest number of PMs ( $7.0 \%)$, due to the accumulation of the $* 4$ allele in their population, followed by the Romanies $(6.0 \%)$ and the Macedonians (4.0\%). The Macedonians stood out as the ethnic group with the highest number of UMs (5.0\%), followed by the Albanians (1.0\%) and the Romanies (1.0\%) (Figure 3).

Concordant genotype-phenotype correlation provides a basis for predicting the phenotype based on genetic testing, which has the potential to achieve optimal pharmacotherapy. Predictive CYP2D6 genotyping is estimated to be beneficial for treatment of about $30.0-40.0 \%$ of CYP2D6 drug substrates, that is for about $7.0-10.0 \%$ of all drugs clinically used.

A study conducted in a psychiatric setting in the USA has shown that the CYP2D6 polymorphisms can have an effect on the cost of treating a patient; patients with ultrarapid and poor metabolizing capacity were found to cost between $\$ 4,000$ and $\$ 6,000$ per year more to treat than EM or IM individuals [28]. Thus, genotyping for individuals receiving single or multiple drugs that are metabolized by CYP2D6 may help clinicians to avoid adverse drug-drug interactions and to individualize better treatment with medications.

In addition, the Food and Drug Administration (FDA) approved testing is now available and an increasing number of medical centers provide this service to patients under their care. It will be increasingly important for doctors, physicians, pharmacists, and other care providers to be able to provide coherent therapeutic recommendations to patients with predetermined pharmacogenetic data.

Following the global trends in pharmacogenetics and the recommendations from the FDA, we decided to conduct this study in order to help with the introduction of pharmacogenetic testing for certain drugs in clinical practice, thus avoiding detrimental drug reactions, facilitating improved drug efficiency and moreover individualizing treatment for each patient. Our study is the first to assess the frequency distribution of the CYP2D6 alleles in the three major ethnic groups living in the Republic of Macedonia, with our findings displaying a genuine correspondence between the prevalence of CYP2D6 allele variants and genotypes in the Republic of Macedonia to other European populations.

Declaration of Interest. The authors report no conflicts of interest. The authors alone are responsible for the content and writing of this article.

\section{REFERENCES}

1. Gardiner SJ, Begg EJ. Pharmacogenetics, drugmetabolizing enzymes, and clinical practice. Pharmacol Rev. 2006; 58(3): 521-590.

2. Nelson DR, Zeldin DC, Hoffman SM, Maltais LJ, Wain HM, Nebert DW. Comparison of cytochrome P450 (CYP) genes from the mouse and human genomes, including nomenclature recommendations for genes, pseudogenes and 
Table 4. Comparison of CYP2D6 allele frequencies in different populations.

\begin{tabular}{|c|c|c|c|c|c|c|c|c|c|c|c|c|c|c|}
\hline \multirow[t]{2}{*}{ Population } & \multirow[t]{2}{*}{ Refs. } & \multicolumn{2}{|c|}{ Functional } & \multicolumn{4}{|c|}{ Non Functional } & \multicolumn{5}{|c|}{ Reduced } & \multicolumn{2}{|c|}{ Duplications } \\
\hline & & $* 1$ & $* 2$ & $* 3$ & $* 4$ & $* 5$ & $* 6$ & $* 9$ & $* 10$ & $* 17$ & $* 29$ & $* 41$ & $* 1 x N$ & $* 2 x N$ \\
\hline French & 15 & 28.00 & 32.00 & 0.00 & 16.00 & 4.00 & 0.00 & 4.00 & 2.00 & 0.00 & 0.00 & 10.00 & 2.00 & 0.00 \\
\hline Sardinian & 15 & 28.60 & 35.70 & 1.80 & 21.40 & 1.80 & 0.00 & 0.00 & 5.40 & 0.00 & 0.00 & 3.60 & 0.00 & 1.80 \\
\hline Russian & 15 & 32.00 & 34.00 & 0.00 & 20.00 & 0.00 & 0.00 & 0.00 & 0.00 & 0.00 & 0.00 & 8.00 & 0.00 & 4.00 \\
\hline German & 32 & 36.40 & 32.40 & 2.00 & 20.70 & 2.00 & 0.90 & 1.80 & 1.50 & - & - & - & 0.50 & 1.30 \\
\hline Croatian & 29 & 76.50 & - & 2.75 & 14.00 & 1.00 & 1.50 & - & - & - & - & - & - & 4.00 \\
\hline Greek & 30 & - & - & 2.30 & 17.84 & - & - & - & - & - & - & - & - & 6.01 \\
\hline Czech & 31 & - & - & 1.12 & 22.87 & 3.14 & 0.02 & - & - & - & - & - & 3.14 & - \\
\hline Bedouin & 15 & 35.70 & 20.40 & 0.00 & 5.10 & 4.10 & 2.00 & 0.00 & 0.00 & 3.10 & 0.00 & 22.40 & 1.00 & 2.00 \\
\hline Macedonian & 27 & 24.90 & 10.80 & 0.80 & 18.70 & 9.10 & 0.00 & 1.60 & 2.70 & - & - & 8.60 & \multicolumn{2}{|c|}{$5.90^{\mathrm{a}}$} \\
\hline Macedonian $^{\mathrm{b}}$ & - & 36.50 & 25.50 & 2.00 & 17.00 & 1.50 & 1.00 & 0.00 & 1.50 & 0.00 & 1.50 & 11.00 & 2.00 & 0.50 \\
\hline Albanian $^{\mathrm{b}}$ & - & 37.00 & 21.50 & 3.50 & 22.50 & 2.50 & 1.50 & 0.50 & 0.50 & 0.00 & 0.00 & 10.50 & 0.00 & 0.50 \\
\hline Romany $^{b}$ & - & 33.00 & 25.40 & 1.50 & 15.00 & 0.50 & 0.50 & 0.50 & 0.00 & 0.00 & 0.00 & 23.00 & 0.50 & 0.00 \\
\hline
\end{tabular}

a The article does not clearly explain on which alleles the duplications occur.

${ }^{\mathrm{b}}$ This study.

alternative-splice variants. Pharmacogenetics. 2004; 14(1): 1-18.

3. Kimura S, Umeno M, Skoda RC, Meyer UA, Gonazalez FJ. The human debrisoquine 4-hydrolase (CYP2D) locus: Sequence and identification of the polymorphic CYP2D6 gene, a related gene, and a pseudogene. Am J Hum Genet. 1989; 45(6): 889-904.

4. The Human Cytochrome P450 (CYP) Allele Nomenclature committee. (http://www.cypalleles. ki.se/ cyp2d6.htm)

5. Steen VM, Andreassen OA, Daly AK, Tefre T, Borresen A-L, Idle JR, et al. Detection of the poor metab-olizer-associated CYP2D6(D) gene deletion allele by long-PCR technology. Pharmacogenetics. 1995; 5(4): 215-223.

6. Johansson I, Lundqvist E, Bertilsson L, Dahl ML, Sjoqvist F, Ingelman-Sundberg M. Inherited amplification of an active gene in the cytochrome P450 CYP2D locus as a cause of ultrarapid metabolism of debrisoquine. Proc Natl Acad Sci USA. 1993; 90(24): 11825-11829.

7. The Pharmacogenomics Knowledge Base (PharmGKB) (https://www.pharmgkb.org/page/cpic).

8. Evans WE, Relling MV. Moving towards individualized medicine with pharmacogenomics. Nature. 2004; 429(6990): 464-468.
9. Ma MK, Woo MH, McLeod HL. Genetic basis of drug metabolism. Am J Health Syst Pharm. 2002; 59(21): 2061-2069.

10. Ingelman-Sundberg M, Oscarson M, McLellan RA. Polymorphic human cytochrome P450 enzymes: An opportunity for individualized drug treatment. Trends Pharmacol Sci. 1999; 20(8): 342-349.

11. Meyer UA. Pharmacogenetics - five decades of therapeutic lessons from genetic diversity. Nat Rev Genet. 2004; 5(9): 669-676.

12. Bradford LD. CYP2D6 allele frequency in European Caucasians, Asians, Africans and their descendants. Pharmacogenomics. 2002; 3(2): 229-243.

13. Tateishi T, Chida M, Ariyoshi N, Mizorogi Y, Kamataki T, Kobayashi S. Analysis of the CYP2D6 gene in relation to dextromethorphan Odemethylation capacity in a Japanese population. Clin Pharmacol Ther. 1999; 65(5): 570-575.

14. Gaedigk A, Gotschall RR, Forbes NS, Simon SD, Kearns GL, Leeder JS. Optimization of cytochrome P4502D6 (CYP2D6) phenotype assignment using a genotyping algorithm based on allele frequency data. Phar-macogenetics. 1999; 9(6): 669-682. 
15. Sistonen J, Sajantila A, Lao O, Corander J, Barbujani G, Fuselli S. CYP2D6 worldwide genetic variation shows high frequency of altered activity variants and no continental structure. Pharmacogenet Genomics. 2007; 17(2): 93-101.

16. Ingelman-Sundberg M. Genetic polymorphisms of cytochrome P450 2D6 (CYP2D6): Clinical consequences, evolutionary aspects and functional diversity. Pharmacogenomics J. 2004; 5(1): 6-13.

17. Soderback E, Zackrisson AL, Lindblom B, A1derborn A. Determination of CYP2D6 gene copy number by pyrosequencing. Clin Chem. 2005; 51(3): 522-531.

18. Lundqvist E, Johansson I, Ingelman-Sundberg M. Genetic mechanisms for duplication and multiduplication of the human CYP2D6 gene and methods for detection of duplicated CYP2D6 genes. Gene. 1999; 226(2): 327-338

19. Lindpaintner K. Pharmacogenetics and the future of medical practice. Br J Clin Pharmacol. 2002; 54(2): 221-230.

20. Kirchheiner J, Nickchen K, Bauer M, Wong ML, Licinio J, Roots I, et al. Pharmacogenetics of antidepressants and antipsychotics: The contribution of allelic variations to the phenotype of drug response (Review). Mol Psychiatry. 2004; 9(5): 442-473.

21. Sistonen J, Fuselli S, Levo A, Sajantila A. CYP 2D6 genotyping by a multiplex primer extension reaction. Clin Chem. 2005; 51(7): 1291-1295.

22. Goddard KA, Hopkins PJ, Hall JM, Witte JS. Linkage disequilibrium and allele-frequency distributions for 114 single-nucleotide polymorphisms in five populations. Am J Hum Genet. 2000; 66(1): 216-234.

23. Rebsamen MC, Desmeules J, Daali Y, Chiappe A, Diemand A, Rey C, et al. The AmpliChip CYP450 test: Cytochrome P450 2D6 genotype assessment and phenotype prediction. Pharmacogenomics J. 2009; 9(1): 34-41.

24. Umamaheswaran G, Dhakchinamoorthi K, Chan-drasekaran A. Distribution of genetic polymorphisms of genes encoding drug metabolizing enzymes \& drug transporters - a review with Indian perspective. Indian J Med Res. 2014; 139(1): 27-65.
25. Al-Dosari M, Al-Jenoobi F, Alkharfy K, Alghamdi A, Bagulb K, Parvez M, et al. High prevalence of CYP 2D6*41 (G2988A) allele in Saudi Arabians. Environ Toxicol Pharmacol. 2013; 36(3): 1063-1067. doi: 10.1016/j. etap.2013.09.008.

26. Qumsieh RY, Ali BR, Abdulrazzaq YM, Osman O, Akawi NA, Bastaki SMA. Identification of new alleles and the determination of alleles and genotypes frequencies at the CYP2D6 gene in Emiratis. PLoS ONE. 2011; 6(12): e28943. doi: 10.1371/journal.pone.0028943.

27. Kapedanovska Nestorovska A, Jakovski K, Naumovska Z, Hiljadnikova Bajro M, Sterjev Z, Eftimov A, et al. Distribution of the most common genetic variants associated with a variable drug response in the population of the Republic of Macedonia. Balkan J Med Genet. 2014; 17(2): 5-14. doi: 10.2478/bjmg-2014-0069.

28. Chou WH1, Yan FX, de Leon J, Barnhill J, Rogers T, Cronin M, et al. Extension of a pilot study: Impact from the cytochrome P450 2D6 polymorphism on outcome and costs associated with severe mental illness. J Clin Psychopharmacol. 2000; 20(2): 246-251.

29. Bozina N, Granić P, Lalić Z, Tramisak I, Lovrić M, Stavljenić-Rukavina A. Genetic polymorphisms of cytochromes P450: CYP2C9, CYP2C19, and CYP2D6 in Croatian population. Croat Med J. 2003; 44(4): 425-428.

30. Arvanitidis K, Ragia G, Iordanidou M, Kyriaki $\mathrm{S}$, Xanthi A, Tavridou A, et al. Genetic polymorphisms of drug-metabolizing enzymes CYP2D6, CYP2C9, CYP2C19 and CYP3A5 in the Greek population. Fundam Clin Pharmacol. 2007; 21(4): 419-426.

31. Buzková H, Pechandová K, Slanar O, Perlik F. Frequency of single nucleotide polymorphisms of CYP-2D6 in the Czech population. Cell Biochem Funct. 2008; 26(1): 76-81.

32. Sachse C, Brockmoller J, Bauer S, Roots I. Cytochrome P450 2D6 variants in a Caucasian population: Allele frequencies and phenotypic consequences. Am J Hum Genet. 1997; 60(2): 284-295. 